Karunathilaka, R.W.I.S., Mallawaarachchi, H. and Rathnayake, R.M.D.I.M., 2021. Hydrofluorocarbon (HFC) management framework for low carbon industrial facilities: Milk processing industry in Sri Lanka. In: Sandanayake, Y.G., Gunatilake, S. and Waidyasekara, K.G.A.S. (eds). Proceedings of the $9^{\text {th }}$ World Construction Symposium, 9-10 July 2021, Sri Lanka. [Online]. pp. 336-346. DOI: https://doi.org/10.31705/WCS.2021.29. Available from: https://ciobwcs.com/papers/

\title{
HYDROFLUOROCARBON (HFC) MANAGEMENT FRAMEWORK FOR LOW CARBON INDUSTRIAL FACILITIES: MILK PROCESSING INDUSTRY IN SRI LANKA
}

\author{
R.W.I.S. Karunathilaka ${ }^{1}$, Harshini Mallawaarachchi ${ }^{2}$ and R.M.D.I.M. \\ Rathnayake $^{3}$
}

\begin{abstract}
Milk processing industry consumes hydrofluorocarbon (HFC) at a great extent. Emission of HFC distresses the food security, water security and the future of healthy living beings. Thus, the purpose of this paper is to propose strategies to improve the HFC management practices in Sri Lankan milk processing industry. Case study method was involved under qualitative phenomenon. Thus, three case studies were selected based on the HFC handling process. Nine milk processing agencies representing three importers and distributors, three milk processors and three service providers were selected to collect the data. Case analysis technique was used for data analysis. Findings revealed that, lack of institutional and national level procedures, unstable governmental policies, and lack of technology have increased the unhealthy handling of HFC in milk processing industry in Sri Lanka. Initiating a national level mechanism for governing HFC importers and service providers, empowering inventers for creating sustainable applications over HFC use and improving awareness were identified as key strategies to eliminate the identified issues under organisational and national level. Accordingly, a framework was proposed, which provides a platform to investigate the status of HFC handling procedure of milk processing industry in Sri Lanka. Since there is a lack of national level concern on managing HFC use in milk processing industry, having a formal framework at national level to govern both national and institutional level procedures was determined as a vital step forward to be considered.
\end{abstract}

Keywords: Hydrofluorocarbon; Hydrofluorocarbon management; Issues; Milk processing; Strategies.

\section{INTRODUCTION}

Climate change and global warming are the most critical challenges faced by the whole world. The emission of greenhouse gases (GHGs) from industries has been affected for both climate change and global warming (Sumathipala, 2015). According to Sathiendrakumar (2003), carbon dioxide $\left(\mathrm{CO}_{2}\right)$, chlorofluorocarbons (CFC), carbon monoxide $(\mathrm{CO})$, methane $\left(\mathrm{CH}_{4}\right)$ and nitrous oxide $\left(\mathrm{N}_{2} \mathrm{O}\right)$ are considered as GHGs. Dunk

\footnotetext{
${ }^{1}$ Department of Building Economics, University of Moratuwa, Sri Lanka, isurusandaruwan5908@gmail.com

${ }^{2}$ Department of Building Economics, University of Moratuwa, Sri Lanka, harshinim@uom.lk

${ }^{3}$ Department of Building Economics, University of Moratuwa, Sri Lanka, dulinirathnayake@gmail.com
} 
(1999) stated that, CFC is the largest single contributor for ozone depletion, which has been developed instead of unpleasant sulphur dioxide and ammonia used in refrigeration compressors more than fifty years ago. HFC was originated as a replacement for both CFCs and HCFCs. According to a study by Mate et al. (2010), CFC and hydrochlorofluorocarbons (HCFC) had been depleted under the Montreal Protocol and thus, the demand for HFC has been increased across the globe. Among greenhouse gases (GHGs), HFC is used for various purposes in the milk processing industry including processing, cooling, chilling and freezing phases for keeping under acceptable environmental condition (O' Brien et al., 2014). Thus, thermal processing and clarification of raw milk, including container-filling phases have shown a high rate of HFC emissions. According to a study by Nutter et al. (2013), milk production industry contributes for generating $2.7 \%$ of GHGs emission globally while enforcing economies. Hence, it has become a grave challenge to reduce the emissions due to high HFC use in milk processing industry. Further, there is a trend of HFC emissions by $10 \%$ to $20 \%$ of carbon equivalent by 2050 because of its escalating demand (O'Brien et al., 2014).

However, very little attention has been paid on managing the HFC use in milk processing industry where no proper national and organisational level integrated mechanism was found for managing the current use of HFC. Hence, this research aims to explore the feasible strategies for managing HFC in milk processing industry. Accordingly, this paper presents a mechanism for managing the HFC use in milk processing industry emphasising the context of Sri Lanka through three objectives; HFC use and its management in milk processing industry, existing strategies, issues and strategies and national level enhancements to manage the HFC use in milk processing industry in Sri Lanka.

\section{LITERATURE SYNTHESIS}

\subsection{Hydrochlorofluorocarbon EMISSION IN MILK ProcesSing INDUSTRY}

According to a study by Hui et al. (2013), a large amount of HFC had been emitted when producing HCFCs. Further to authors, there is no specialised procedure which can be followed for monitoring and controlling HFC emission. As Velders et al. (2015) further stated, HFC production and consumption had been rapidly increased from $20 \%$ to $40 \%$ in China related to recent years. Apart from that, HFC mainly emits in food processing industry, fishing industry, poultry farms, milk processing industry, meat-processing industry and fire-fighting equipment production industry (Sumathipala, 2015). In milk processing industry, the HFC emission sources can be identified by referring to the way of using HFC based appliances in milk processing phases (Ulrich et al., 2013). Thus, the current use of HFC can be recognised during its importation, operation, maintenance and disposal stages. During the operational stage, HFC emissions can be occurred through different sources related to air conditioning and refrigeration phases of milk processing plants. According to a study by O' Brien et al. (2014), HFC is used for milk processing, cooling, chilling and freezing phases to keep the product under acceptable environmental conditions. Refrigerant losses from trucks and machines in the process can also be highlighted as the main HFC emitting sources of milk processing. Refrigerant leakages can be occurred during operations and standstill periods due to permeation through hoses and diffusion past fittings and seals (Zhan et al., 2014). Typically, raw milk is delivered by insulated refrigerated trucks with tanks from one or more farms to a processor. 
Leakages of refrigerant can be occurred when milk is transported from one place to another through trucks (Ulrich et al., 2013). Further, refrigerant losses can be occurred through cold rooms and refrigerated warehouses, milk storage tanks and chillers at milk processing plants (Tang et al., 2017).

\subsection{HFC EMISSION In SRI LANKAN MiLK Processing INDUSTRY}

According to Dayaratne and Gunawardana (2015), Sri Lanka contributes for emitting GHGs including HFCs related to many industrial sectors including milk processing industry. HFC usage has been increased over the years with respect to milk processing. According to a national survey on HFC use in Sri Lanka, there are seven main milk processing plants in the country, which mainly use HFC-134a based chilling tanks for the process (Sumathipala, 2015). Currently, Sri Lanka is about 15-20 percent self-sufficient with its milk products, though that level has been achieved mostly with imported milk powder. Total milk production in 2005 was an estimated 162 million litres, up 3 percent from the previous year, with approximately 13.6 million litres supplied by dairy cows. Of this growth, 98.9 million litres (47 percent) of local milk entered the formal market (Abeykoon et al., 2016). According to data gathered, the consumption of HFC has been increased from 496 tonnes in 2011 to 587 tonnes in 2014, an average annual growth rate of $6 \%$ (Sumathipala, 2015). HFC consumption is expected to continue to grow in next decade, by at least 40-50 tonnes and perhaps as much as 80-100 tonnes a year. However, no proper mechanism has been adapted yet at both national and organisational levels for managing HFCs in milk processing industry.

\subsection{HFC Management Practices}

Various strategies have been applied across the globe to manage the HFC use. Denmark has used various climate and ozone friendly refrigeration technologies to reduce carbon emissions (Ciconkov, 2018). As stated by Liu et al. (2015), increased social consideration on achieving environmental goals and environmentally friendly technologies for appliances based on HFCs can be considered as other mechanisms. According to Velders et al. (2015), the Montreal Protocol was the first international agreement adapted to HFC management almost universally concerning any environmental matter. The Protocol was based on a proven, consistent, and well understood framework that allows the global community to greatly reduce greenhouse gases including HFC emissions while ensuring that consumers and businesses experience a smooth transition to newer, more sustainable products. Moreover, Kyoto Protocol was ratified by Japan in June 2002 which came into force since February 2005 and this protocol was an international and legally binding agreement to reduce greenhouse gases (GHGs) including HFCs emissions worldwide. A summary of practices, which have been introduced for managing HFC globally are presented in Table 1.

Accordingly, by considering the strategies and issues related to the HFC use across the globe, this study focuses on investigating the current status of HFC management practices in milk processing industry in Sri Lanka. Thus, the conceptual framework was firstly developed, which guided the authors to investigate the current strategies and issues of HFC management procedures in milk processing industry as illustrated in Figure 1.

As illustrated in Figure 1, The conceptual model is used as a basis to investigate the current status of HFC handling in milk processing industry in Sri Lanka. Thus, the national and organisational level directions were considered for establishing a proper 
integrated mechanism for HFC handling. Three aspects, such as, role of government, technology adaptation and value for business, which were identified through literature were initially considered at the national level. Main three stages of HFC handling; importation and transportation, operation and maintenance, and disposal were considered for investigating the current strategies and issues at the organisational level.

Table 1: Practices of HFC management

\begin{tabular}{|c|c|}
\hline Source & Strategies \\
\hline \multirow[t]{2}{*}{ Montreal Protocol } & $\begin{array}{l}\text { Provisions introduced for shifting from HFCs, which has got high } \\
\text { global warming potentials to alternatives }\end{array}$ \\
\hline & $\begin{array}{l}\text { Provides a proven, consistent, and well understood framework to } \\
\text { greatly reduce GHGs including HFC }\end{array}$ \\
\hline Kyoto Protocol & $\begin{array}{l}\text { An international and legally binding agreement to reduce GHGs } \\
\text { Introduced the mechanisms for reducing HFCs emissions }\end{array}$ \\
\hline $\begin{array}{l}\text { Clean Development } \\
\text { Mechanism (CDM) }\end{array}$ & $\begin{array}{l}\text { Global adoption of technologies has been introduced for reducing } \\
\text { carbon emissions }\end{array}$ \\
\hline The UNFCCC & $\begin{array}{l}\text { Provides the guidelines for reporting emissions and meeting emission } \\
\text { reductions targets }\end{array}$ \\
\hline
\end{tabular}

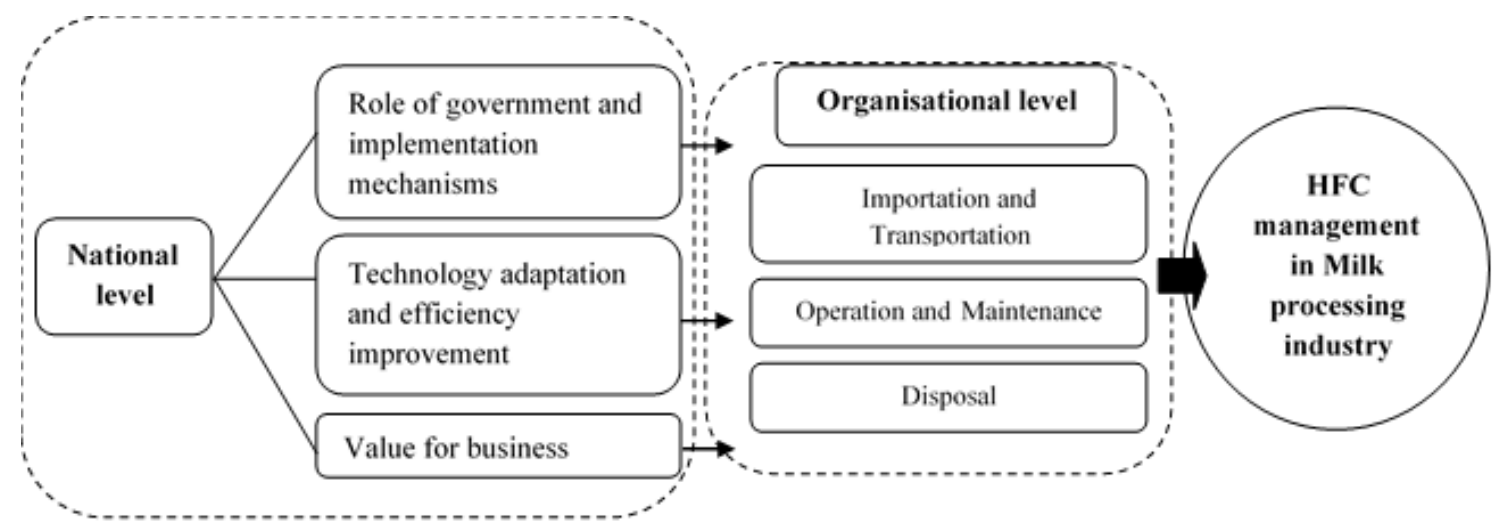

Figure 1: The conceptual framework

The research methodology adapted in this research is described below.

\section{METHODOLOGY}

Qualitative approach was involved to explore the existing issues and strategies for managing HFC in milk processing industry in Sri Lanka. Among the various research methods case study method was selected in this research because the research problem is required an in-depth investigation. Apart from that, case study approach is more appropriate to bringing an understanding of a complex issue or object and can extend experience or add strength to what is already known through previous research (Yin, 2014). As Yin (2014) stated, the number of cases can be one to eight depending on the nature of the research. Thus, three cases, which are based on the HFC handling process: (i) Importation and transportation, (ii) Operation and maintenance and (iii) Disposal, were selected. 'Agency' is considered as unit of analysis in each case. Thus, nine (09) agencies that have actively involved in HFC handling were selected to collect the data as shown in Table 2. 
The collected data were analysed by using case analysis technique considering each individual case study as a separate study.

Table 2: Profile of case study interviewees

\begin{tabular}{|c|c|c|c|c|c|}
\hline Case & $\begin{array}{l}\text { Stages of HFC } \\
\text { handling }\end{array}$ & Agency & Type & Designation & $\begin{array}{c}\text { Years of } \\
\text { experience }\end{array}$ \\
\hline \multirow[t]{3}{*}{$\begin{array}{c}\text { Case } \\
\text { A }\end{array}$} & \multirow[t]{3}{*}{$\begin{array}{l}\text { Importation and } \\
\text { Transportation }\end{array}$} & A1 & $\begin{array}{l}\text { Importer and } \\
\text { distributor }\end{array}$ & Transport and logistics manager & 8 years \\
\hline & & A2 & $\begin{array}{l}\text { Importer and } \\
\text { distributor }\end{array}$ & Supply chain manager & 5 years \\
\hline & & A3 & $\begin{array}{l}\text { Importer and } \\
\text { distributor }\end{array}$ & Transport and logistics manager & 12 years \\
\hline \multirow{6}{*}{$\begin{array}{c}\text { Case } \\
\text { B }\end{array}$} & \multirow[t]{6}{*}{ Operation and Use } & \multirow[t]{3}{*}{ B1 } & \multirow{3}{*}{$\begin{array}{l}\text { Milk } \\
\text { processor }\end{array}$} & Supply chain director & 10 years \\
\hline & & & & Engineering manager & 5 years \\
\hline & & & & Mechanical engineer & 4 years \\
\hline & & \multirow[t]{2}{*}{ B2 } & \multirow{2}{*}{$\begin{array}{l}\text { Milk } \\
\text { processor }\end{array}$} & Chief engineer & 5 years \\
\hline & & & & Technical supervisor & 6 years \\
\hline & & B3 & $\begin{array}{l}\text { Milk } \\
\text { processor }\end{array}$ & $\begin{array}{l}\text { Technician } \\
\text { Engineering manager } \\
\text { Mechanical engineer } \\
\text { Technical supervisor }\end{array}$ & $\begin{array}{l}9 \text { years } \\
5 \text { years } \\
6 \text { years } \\
8 \text { years }\end{array}$ \\
\hline \multirow[t]{3}{*}{$\begin{array}{c}\text { Case } \\
\mathrm{C}\end{array}$} & \multirow[t]{3}{*}{$\begin{array}{l}\text { Maintenance and } \\
\text { Disposal }\end{array}$} & $\mathrm{C} 1$ & $\begin{array}{l}\text { Service } \\
\text { provider }\end{array}$ & Maintenance engineer & 12 years \\
\hline & & $\mathrm{C} 2$ & $\begin{array}{l}\text { Service } \\
\text { provider }\end{array}$ & Mechanical engineer & 5 years \\
\hline & & $\mathrm{C} 3$ & $\begin{array}{l}\text { Service } \\
\text { provider }\end{array}$ & Mechanical engineer & 3 years \\
\hline
\end{tabular}

\section{RESULTS AND DISCUSSION}

The investigations were made into three key stages: (i) Importation and transportation, (ii) Operation and maintenance, and (iii) Disposal of HFC. The enhancements, which can be considered at national level were also proposed relating to three key constraints: (i) Role of government and implementation mechanisms, (ii) Technology adaptations and efficiency improvement and (iii) Value for business, for managing HFC use in milk processing industry. The case analysis and findings are presented under three headings: (i) Existing strategies, (ii) Issues and (iii) Proposed strategies, for managing HFC in milk processing industry in each case. As the next step, the national level strategies were also recognised under three constraints: (i) Role of government and implementation mechanisms, (ii) Technology adaptations and efficiency improvement and (iii) Value for business.

\subsection{Case Analysis - CaSe A (IMPORTAtion AND Transportation)}

\subsubsection{Existing Strategies}

Case A has their own procedure to manage HFC operations. According to Transport and Logistics Manager “according to organisation's regulations, importers should register and obtain the certificate and license for importing HFC. We are generally maintaining our certifications". Furthermore, having insurance coverage for purchasing the stock of cylinders and obtaining declaration from customs are other formal strategies used. In transportation, vehicles are labelled by using proper signage since it is a legal 
requirement. Further, daily mandatory checks are conducing on the leaks and repairs of transporting vehicles.

\subsubsection{Issues}

Absence of specific procedure for HFC importation and transportation was identified as a main issue in case A. This is further explained by Transportation and Logistics Manger as "currently we are using a common procedure, but it is not specifically design for a milk processing industry". Findings revealed that there is no national level mechanism or specific guideline for assisting and governing HFC handling organisations. Most importantly, organisations have faced difficulties due to the time-consuming procedure adapted by customs when releasing imported HFC. Not having enough space for storing before transportation and not considering safety and quality requirements for storing HFC are other issues found through case analysis.

\subsubsection{Proposed Strategies}

Introducing national level mechanism for governing HFC importers, and updated policies and standards relating to modern technologies are two essential strategies stated by experts in case A. Supply Chain Manager stated that "existing policies and standards of HFC should be updated relating to different industries and modern technology". As he further stated, training programs should be introduced for the custom officers to enhance the knowledge on HFC and to prevent delays.

\subsection{Case Analysis - CaSe B (OPERATion ANd Maintenance)}

\subsubsection{Existing Strategies}

Involvement of service providers in the operation and use phase in terms of establishing agreements can be identified as a strategy. Continuous maintenance schedules and routine programmes can be followed to investigate the proper working condition of HFCs and to prevent fault with HFC based appliances. Further, organising technical programmes with the support of service providers to enhanced knowledge on operating procedures is another strategy as identified by Mechanical Engineer of case B. Further, automated systems used for getting readings and status on HFC working condition is used as a strategy of operation and maintenance stage.

\subsubsection{Issues}

Engineering Manager of case B identified that the difficulty in keeping the acceptable gas level within machines and risk of changing coolant level of air conditioning and refrigeration systems are main issues faced in operation and maintenance. Technician of case B stated another issue as, "types of gases may be changed time to time according to the technology and our old gases such as CFCs have to be replaced into another gas, because of changing laws and technology". HFC refilling process is also recognised as a critical issue when the composition of HFC had been changed through leaking and it is supported to create an unhealthy environment for raw milk and dairy products. Evaporation is another critical issue in operation and use of the HFC in milk processing plants.

\subsubsection{Proposed Strategies}

Conducting training programs for service providers, implementing a proper communication system and recruiting well experienced experts for detecting faults in 
HFC handling can be introduced as strategies. Engineering Manager of case B3 mentioned that the service providers should be properly selected for system installation works and, the continuous inspections should be followed to ensure zero faults and leakages. Moreover, a proper maintenance procedure should be followed to ensure the operation of HFC based appliances.

\subsection{Case Analysis - Case C (Disposal)}

\subsubsection{Existing Strategies}

Maintenance Engineer of case $\mathrm{C}$ stated that "we hold cylinder stock under our warehouse and normal temperature is maintained within them complying with the relevant safety rules, such as using a covered area as the warehouse and access should be limited for the safety name in few". As Mechanical Engineer of case C further stated, applying explosive proof cabinets to store cylinders, installing all shelves within a covering space, storing in a locked cage are other strategies used. Mechanical Engineer of case C2 stated that "normally HFCs are not disposed and empty cylinders are handed over to suppliers to get refilled. Moreover, installation of combustible gas detectors and monitors for detecting leaks of cylinders can be highlighted as another strategy".

\subsubsection{Issues}

The disposal of HFC suffers a several issues in existing practice. Not having a proposer disposing mechanism for used cylinders and the risk of occurring short term and longterm diseases were the main issues identified in selected agencies. Maintenance Engineer of case $\mathrm{C}$ mentioned that "beyond short term diseases, long terms diseases can be occurred because of handling HFC based cylinders and appliances can impact to our staff remembers".

\subsubsection{Proposed Strategies}

Introducing updated and flexible methods to store HFC is one of strategies proposed. Awareness should be raised among the workers about the proper handling of HFC while loading, unloading and storing. Further, Mechanical Engineer of case $\mathrm{C}$ stated that "new technology should be introduced for storing HFC to get maximum benefits through loading and unloading". Proper use of personal protective equipment (PPE) should be a rule among the workers while handling HFC during disposal as suggested by the Maintenance Engineer of case $\mathrm{C}$.

As the next stage, national level enhancements were also proposed based on case analysis.

\subsection{NATIONAL LEVEL ENHANCEMENTS TO MANAgE HFC USE IN MILK PROCESSING INDUSTRY}

Interviewees of cases were highlighted that organisational level strategies can be easily implemented because those factors are within their control. Even though, individual cases cannot control the factors regarding national level, interviewees of cases suggested enhancements regarding national level for handling HFC in milk processing industry in Sri Lanka. The key factors, such as role of government, implementation mechanism, technology, efficiency improvement and value for business, which represent a vital role in managing the HFC use in milk processing industry, were considered to enhance at national level. 


\subsubsection{Role of Government and Implementation Mechanism}

Special attention of the government and the other regulatory bodies should be paid to empower the HFC management process. As stated by Supply Chain Manager of case A, "updated policies and standards should be presented relevant to new technologies and common data base should be introduced and maintained to keep records of HFC use". As stated by Maintenance Engineer of case $\mathrm{C}$, there is a necessity of having a formal framework in line with updated policies and standards related to HFC based appliances. Supply Chain Director of case B1 further mentioned "appointing a special team to provide the training programs for the HFC handling agencies is an important strategy to be established. Further, continuous auditing procedures should be followed to ensure the proper implementation of strategies".

\subsubsection{Technology Adaptation and Efficiency Improvements}

Engineering Manager of the case B proposed "new resources with technology should be introduced for the betterment of the field". Further, HFC was the existing refrigerant, which showed a high use compared to other refrigerants. Thus, effectiveness and efficiency improvements of the HFC use can be considered in milk processing. Supply Chain Manager of case A stated "new gases which are environmentally friendly, and more efficiency should be introduced". Thus, inventors should be encouraged by providing facilities to improve the efficiency of HFC based appliances in milk processing. Hence, introducing updated technologies and adequate resources was recognised as a necessity at national level to establish a proper HFC management mechanism.

\subsubsection{Value for Business}

At present, low-cost procedures are followed by organisations to enhance the profit. Transport and Logistic manager of case A stated "companies should be encouraged to follow environmentally friendly methods considering the social responsibility while seeking their own profits". Thus, encouraging companies for following environmentally friendly methods and social responsibility raising can be considered at national level.

As the case study findings revealed, the handing process of HFC use in milk processing should have a due consideration in adopting national and organisational level strategies for its better management. Thus, a framework for managing the HFC use in milk processing industry was proposed based on the key findings of the research. The proposed framework is illustrated in Figure 2.

Figure 2 clearly displays the issues and strategies, which were derived through case analysis under three main stages: (i) Importation and transportation, (ii) Operation and maintenance and (iii) Disposal of HFC. Moreover, the factors related to national level aspects such as; role of government, technology adaptation and value for business were also presented which will govern the milk processing industry towards the better management of HFC. 


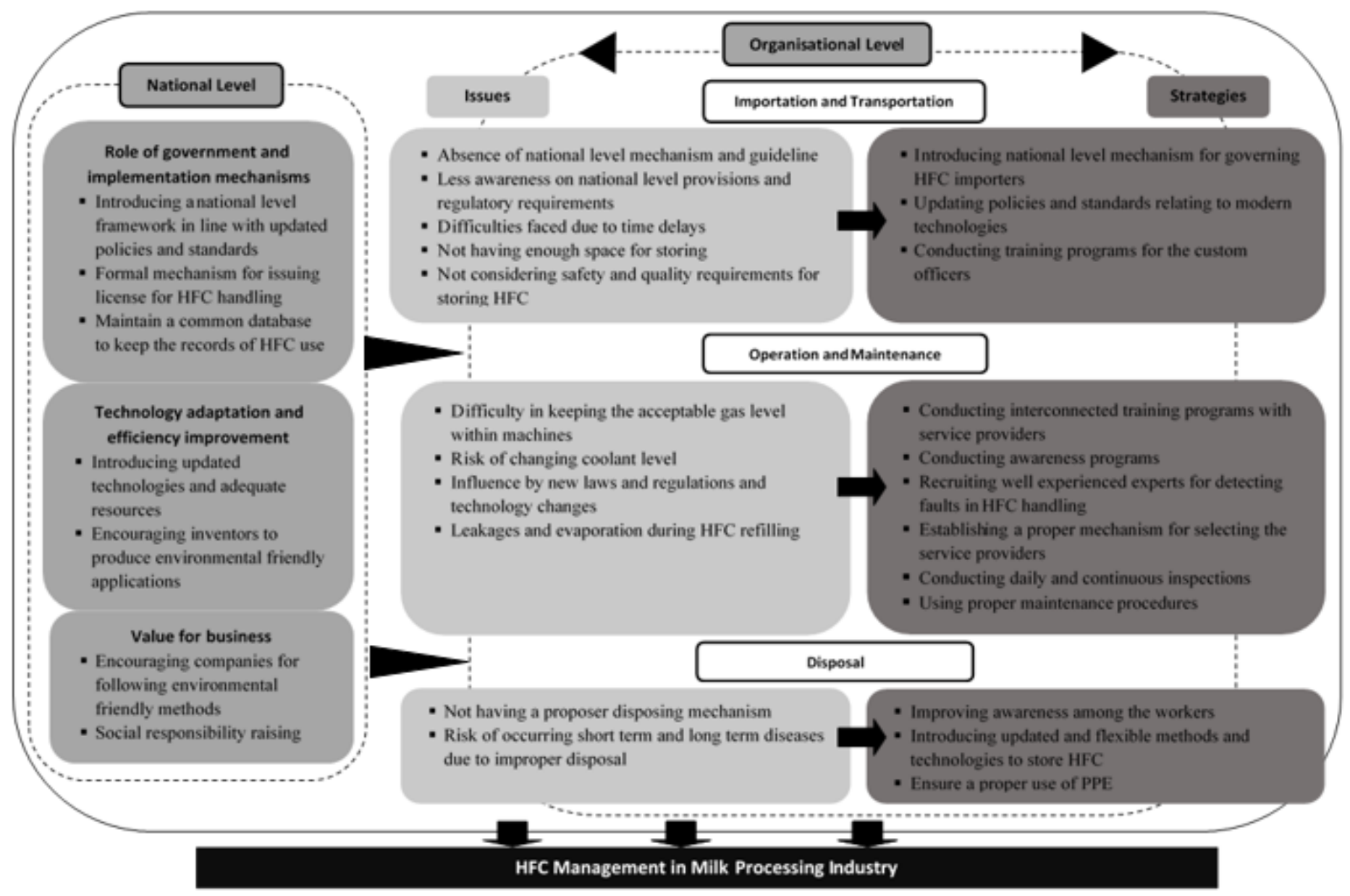

Figure 2: Framework for managing the HFC use in milk processing industry in Sri Lanka 


\section{CONCLUSIONS}

Dairy industry has become one of critical sectors in country's economy. However, little attention has been paid up on managing the HFC use with respect to milk processing industry. The significance of study became obvious since the scholars stated the effect of the heavy use of HFC in milk processing industry for milk processing, cooling, chilling and freezing phases. Significantly, the issues in existing process were identified specially relating to HFC importation, transportation, operation and maintenance, and disposal. Introducing national level mechanism for governing HFC importers, conducting interconnected training programmes with service providers and introducing updated technologies to store HFC were suggested as strategies to overcome the identified barriers at organisational level. Apart from that, strategies, which are currently used in other countries, such as introducing climate and ozone friendly HFC technologies and increasing social consideration on HFC handling, were also identified as important strategies to adopt in Sri Lanka. Indeed, lack of national level concern has hindered the proper management of HFC use thus, having a formal framework at national level to govern both national and institutional level procedures was proposed. Further, the developed framework can be applied to establish a smooth and well scheduled HFC management procedure in milk processing industry in Sri Lanka.

\section{REFERENCES}

Abeykoon, C.D., Rathnayake, R.M.C., Johansson, M., Silva, G.L.L.P., Ranadheera, C.S., Lundh, Å. and Vidanarachchi, J.K., 2016. Milk coagulation properties and milk protein genetic variants of three cattle breeds/types in Sri Lanka. Procedia Food Science, 6, pp.348-351.

Ciconkov, R., 2018. Refrigerants: There is still no vision for sustainable solutions. International Journal of Refrigeration, 86, pp.441-448.

Dayaratne, S.P. and Gunawardana, K.D., 2015. Carbon footprint reduction: a critical study of rubber production in small and medium scale enterprises in Sri Lanka. Journal of Cleaner Production, 103, pp.87-103.

Dunk, A.S., 1999. An examination of the role of financial investment appraisal methods in the context of international environmental regulation. Accounting, Auditing \& Accountability Journal, 12(2), pp.188205.

Hui, L., Yong-Li, C. and Li-Rong, Y., 2013. Analysis of potential for HFC-23 emission reduction in China's fluorine chemical industry. Advances in Climate Change Research, 4(4), pp.260-266.

Liu, X., Yu, J. and Yan, G., 2015. Theoretical investigation on an ejector-expansion refrigeration cycle using zeotropic mixture R290/R600a for applications in domestic refrigerator/freezers. Applied Thermal Engineering, 90, pp.703-710.

Maté J., Papathanasopoulos C. and Latif S. 2012. Cool technologies: working without HFCs. Amsterdam: Greenpeace.

Nutter, D.W., Kim, D.S., Ulrich, R. and Thoma, G., 2013. Greenhouse gas emission analysis for USA fluid milk processing plants: Processing, packaging, and distribution. International Dairy Journal, 31, pp. S57-S64.

O’Brien, D., Capper, J.L., Garnsworthy, P.C., Grainger, C. and Shalloo, L., 2014. A case study of the carbon footprint of milk from high-performing confinement and grass-based dairy farms. Journal of Dairy Science, 97(3), pp.1835-1851.

Sathiendrakumar, R., 2003. Greenhouse emission reduction and sustainable development. International Journal of Social Economics, 30(12), pp.1233-1248.

Sumathipala K., 2015. National Survey on HFC Use in Sri Lanka. [Online] Undp.org. Available from: https://www.undp.org/content/dam/undp/library/Environment\%20and\%20Energy/Ozone\%20and\%20 Climate/Sri\%20Lanka\%20HFC\%20Inventory.pdf [Accessed 5 May 2019]. 
Tang, W., He, G., Cai, D., Zhu, Y., Zhang, A. and Tian, Q., 2017. The experimental investigation of refrigerant distribution and leaking characteristics of R290 in split type household air conditioner. Applied Thermal Engineering, 115, pp.72-80.

Ulrich, R., Thoma, G., Nutter, D. and Wilson, J., 2013. Tailpipe greenhouse gas emissions from tank trucks transporting raw milk from farms to processing plants. International Dairy Journal, 31, pp. S50-S56.

Velders, G.J., Fahey, D.W., Daniel, J.S., Andersen, S.O. and McFarland, M., 2015. Future atmospheric abundances and climate forcings from scenarios of global and regional hydrofluorocarbon (HFC) emissions. Atmospheric Environment, 123, pp. 200-209.

Yin R. K., 2014. Case study research, design and methods. $5^{\text {th }}$ ed., Sage: Los Angeles.

Zhan, T., Potts, W., Collins, J.F. and Austin, J., 2014. Inventory and mitigation opportunities for HFC-134a emissions from nonprofessional automotive service. Atmospheric Environment, 99, pp.17-23. 